\title{
Curcumin, inflammation, ageing and age-related diseases
}

\author{
E Sikora ${ }^{1 *}$, Giovanni Scapagnini $^{2}$, Mario Barbagallo ${ }^{3}$
}

\begin{abstract}
A Symposium regarding the Pathophysiology of Successful and Unsuccessful Ageing was held in Palermo, Italy between April 7 and $8^{\text {th }}$ 2009. Here the lecture by Sikora with some input from the chairpersons Scapagnini and Barbagallo is summarized. Ageing is manifested by the decreasing health status and increasing probability to acquire age-related disease such as cancer, Alzheimer's disease, atherosclerosis, metabolic disorders and others. They are likely caused by low grade inflammation driven by oxygen stress and manifested by the increased level of pro-inflammatory cytokines such as IL-1, IL-6 and TNF- $\alpha$, encoded by genes activated by the transcription factor $\mathrm{NF}-\kappa \mathrm{B}$. It is believed that ageing is plastic and can be slowed down by caloric restriction as well as by some nutraceuticals. Accordingly, slowing down ageing and postponing the onset of age-related diseases might be achieved by blocking the NF- $\kappa \mathrm{B}$-dependent inflammation. In this review we consider the possibility of the spice curcumin, a powerful antioxidant and anti-inflammatory agent possibly capable of improving the health status of the elderly.
\end{abstract}

\section{Background}

A Symposium regarding the Pathophysiology of Successful and Unsuccessful Ageing was held in Palermo, Italy between April 7-8 ${ }^{\text {th }} 2009$. Comments and keynotes by E. Sikora, G. Scapagnini and M. Barbagallo are summarized here.

\section{Ageing and age-related diseases}

The ageing process, opposite to longevity, is not genetically programmed. There are no genes that have been selected to actually promote ageing. The theory of evolution assumes that there is a trade-off between body maintenance and investment in reproduction [1]. Lifespan is regulated by genes controlling the activity of metabolism, antioxidant systems, DNA repair, cellular senescence and cell death. Their functions gradually decline due to random errors in DNA replication and damage to macromolecules, what leads to the accumulation of senescent cells and damaged tissue with age. However, diverse tissues building various organs may show different patterns of senescence [2-4]. The lesions accumulating with age are mainly, but not exclusively, caused by the increasing level of reactive oxygen species (ROS), as originally proposed by Harman [5].

\footnotetext{
* Correspondence: e.sikora@nencki.gov.pl
'Laboratory of Molecular Bases of Ageing, Nencki Institute of Experimental

* Correspondence: e.sikora@nencki.gov.pl
'Laboratory of Molecular Bases of Ageing, Nencki Institute of Experimental Biology, PAS, Warsaw, Poland
}

(C) 2010 Sikora et al; licensee BioMed Central Ltd. This is an Open Access article distributed under the terms of the Creative Commons Attribution License (http://creativecommons.org/licenses/by/2.0), which permits unrestricted use, distribution, and reproduction in any medium, provided the original work is properly cited. cence which may play a part in the age-related immunological changes [6]. Lifelong exposure to a plethora of antigens (bacterial, viral, exogenous, auto, which can be considered as stressors) leads to a gradual decline of naive $\mathrm{T}$ cells. In turn, there is an accumulation of memory $\mathrm{T}$ and effector $\mathrm{CD} 8+\mathrm{CD} 28-\mathrm{T}$ cells which secrete increased amounts of pro-inflammatory cytokines [7]. antigens is the progressive activation of macrophages and related cells in most organs and tissues of the body creating an imbalance between inflammatory and antiinflammatory networks. This results in the low grade chronic pro-inflammatory status (inflamm-ageing) [6]. Inflamm-ageing can be characterized by an increased level of a variety of pro-inflammatory cytokines in tissues, and other inflammatory markers, such as coagulation cascade components, and the presence of viral infections caused by the following viruses: CMV and Epstein Barr virus (EBV) [8]. Cellular participants in low-grade inflammatory status not only include cells of the immune sytem but also other ones which have undergone genotoxic stress-induced senescence and secrete many inflammatory cytokines, to the so-called senescence-associated secretory phenotype (SASP) [9].

Ageing, although not a disease by itself, makes the organism vulnerable to a plethora of them. Holliday Another major consequence of chronic exposure to 
claims that many age-related changes can not be distinguished from age-related diseases [10]. Indeed, it seems that many age-related pathologies share the signalling pathways with the process of ageing. It has been proposed that low-grade inflammation may not be the cause of ageing itself (inflamm-ageing and SASP), but also of many age-related diseases [11-13].

Several lines of evidence have led to the general acceptance of a link between inflammation and cancer. Generally, cancer and inflammation are connected by two pathways: the intrinsic and the extrinsic one. The intrinsic pathway means that oncogene activation induces in transformed cells the production of inflammatory mediators, mainly via the activation of the transcription factor NF- $\kappa \mathrm{B}$. Conversely, in the extrinsic pathway inflammatory or infectious conditions augment the risk of cancer development. Epidemiological studies have shown that chronic inflammation predisposes individuals to various types of cancer [14]. Recently inflammation has been proposed as the seventh feature of cancer [15] which should be added to the six canonical previously proposed ones [16].

Inflammation is also considered to be a critical initial step in the development of atherosclerosis [13]. The early phase of atherogenesis is characterized by the attraction/adherence of monocytes to the vascular endothelium and their migration into the vessel wall. The expression of cellular adhesion molecules promotes the adhesion of leukocytes to the vascular endothelium and is induced by inflammatory factors, including IL-1, TNF-a, and CRP. Furthermore, the progressive accumulation of macrophages and their uptake of oxidized LDL ultimately leads to the generation of the so called foam cells and initiation of fatty streaks [12]. It seems that $\mathrm{NF}-\kappa \mathrm{B}$ is the main mediator of inflammation and endothelial dysfunction in the elderly [17].

An inflammatory state has been documented in senile plaques and surrounding glia with an increased expression of the acute phase protein CRP as well as proinflammatory interleukins such as IL- 6 and IL- 1 in Alzheimer's disease (AD) patients and animal models [18]. The evidence of inflammatory mechanisms being involved in $\mathrm{AD}$ is also based on the fact that certain anti-inflammatory drugs could modify the course of the disease $[19,20]$.

Obesity, insulin resistance and type 2 diabetes are also closely associated with chronic inflammation. Exposure to excess amounts of nutrients and energy can reactivate the ancient inflammatory potential of metabolically important tissues. The adipose tissue of obese individuals has in fact been shown to produce higher levels of the pro-inflammatory cytokines (TNF, IL-6) and other pro-inflammatory factors [21].
The assumption of a link between ageing and agerelated diseases raises the pivotal question of whether concentrating the effort on just curing the age-associated diseases is the optimal approach to making our later lives more healthy and comfortable. Indeed, a new strategy hopefully leading to healthy ageing has been proposed. Recently, it has been postulated that interventions aimed at slowing down ageing could offer a much greater benefit than those targeted at individual diseases [22]. The evolutionary theory of disposable soma suggests that ageing is unavoidable but malleable and plastic [23] and perhaps this may be possible by dietary or pharmaceutical intervention or genetic alteration, to extend the lifespan [22].

\section{Curcumin as an anti-inflammatory agent}

Nutraceuticals are food ingredients which either have a proven physiological benefit or provide protection against chronic diseases. They may contribute to the prevention of diseases and ageing. Diet has a major role in modulating the risk of development of several diseases and successful ageing. Edible plants, amongst dietary constituents, are important in that they contain phytochemicals which can control biochemical processes at cellular level of animal organism.

Among nutraceuticals, the role of curcumin is supported by a number of scientific evidence that have confirmed its anti-inflammatory and anti-oxidant actions both in vivo and in vitro. Curcumin is the phytochemical derived from the rhizome of Curcuma longa, present in the spice turmeric and it gives Indian curry its yellow color. Curcumin has been used for millennia as a wound-healing agent and for treating a variety of diseases in traditional Indian and Chinese medicine. Recently, it has attracted the attention of researchers as an agent capable of inhibiting the proliferation of cancer cells and/or inducing many signaling pathways leading to various modes of cell death [24,25]. As a cell death inducer curcumin has gained profound interest as a chemopreventive and anti-cancer agent which found confirmation in many in vitro experiments and preclinical studies on animal models.

Furthermore curcumin rises interest as an agent of potential use in therapy of many diseases (not only cancer) with an inflammation constituents including cardiovascular diseases, Alzheimer's disease, rheumatoid arthritis and metabolic syndrome. Although only a few worldwide clinical trials are underway now [26], a plethora of studies using animal and cell line models have been undertaken to elucidate the molecular mechanisms and biological effects of curcumin.

Curcumin has an unprecedented number of molecular targets justifying its chemopreventive, antioxidant and anti-inflammatory activities (reviewed recently in 
$[27,28]$. Briefly, these targets include transcription factors with AP-1 described as the first one, and others such as SP-1, p53, STAT-3, ATF3, Nrf2, PPAR- $\gamma$, CHOP, HIF-1 $\alpha, \beta$-catenin and NF- $\kappa \mathrm{B}$, enzymes such as protein kinases (PKA, PKC, FAK, Src), glutathione $S$ transferase, DNA topoisomerase-II, telomerase, hemeoxygenase-1, p300 histone acetyltransferase, metaloproteinases, lipoxygenase (5-LOX), cyclooxygenase-2 (COX2 ) and others. The most far-reaching physiological consequences seem to stem from the action of curcumin as an inhibitor of the activity of the transcription factor $\mathrm{NF}-\kappa \mathrm{B}$. The NF- $\kappa \mathrm{B}$ transcription factor is a master regulator of the inflammatory process which activates the expression of many pro-inflammatory cytokines, such as TNF- $\alpha$, IL- $1 \beta$ and IL- 6 . Some of the NF- $\kappa$ B-induced proteins, like TNF- $\alpha$, are also its activators, which is particularly important in the chronic inflammatory state. $\mathrm{NF}-\kappa \mathrm{B}$ seems to be the culprit of inflammageing, since this signaling system integrates the intracellular regulation of immune responses in both ageing and agerelated diseases [29].

Many activities of curcumin can be also explained by its ability to suppress acute and chronic inflammation by scavenging reactive oxygen and reactive nitrogen species and enhancing antioxidant defense (i.e. by increasing glutathione level). However, curcumin is not only a simple antioxidant, but as a electrophilic compound it triggers the Nrf2/ARE signaling pathway which plays a key role in activating antioxidative enzymes, phase 2 enzymes and so - called vitagens (heme oxygenase, Hsp70, thioredoxin reductase and sirtuins), which might have a pivotal role in oxidative stress-induced diseases [30].

The amount of data documenting beneficial effects of curcumin in protecting against different diseases, particularly those which are related to age are increasing. It seems that extraordinary potency of curcumin, which makes it an almost universal remedy, results from the inflammatory origins of many diseases and curcumin's anti-inflammatory activity.

Despite the practical lack of data showing curcumin's influence on ageing and lifespan, there is a strong rational argument suggesting that curcumin can influence the process of senescence and ageing retardation [25].

\section{Curcumin and AD}

Recently curcumin has been proposed as a potential remedy against brain ageing and neurodegenerative disorders [31], and it has been evaluated in a pilot clinical trial in $\mathrm{AD}$ patients, with encouraging preliminary results [32]. Curcumin is highly lipophilic and might cross the blood-brain barrier (BBB) to reach the brain. Although its bioavailability is very low, since the drug is rapidly metabolized by conjugation, curcumin may reach brain in a sufficient concentration to activate signal transduction events and to decrease $A \beta$ aggregation [33]. Epidemiological studies suggested that curcumin, one of the most prevalent nutritional and medical compounds used by the Indian population, is responsible for the significantly reduced (4.4-fold) prevalence of AD in India compared to United States [34]. Furthermore elderly Singaporeans who ate curry with turmeric had higher Mini-Mental State Examination scores than those who did not [35].

\section{Conclusions}

Curcumin can counteract the pro-inflammatory state which is believed to participate in many age-related diseases. In fact, it seems that curcumin directly affects a few major targets, just like ROS scavenging and production and the NF- $\kappa \mathrm{B}$ signaling pathways, which can in turn suppresses the pro-inflammatory state involved in the etiology of ageing and age-related diseases.

The main concern regarding the therapeutic value of curcumin is its poor bioavailability, which, on the other hand, assures lack of toxicity even when consumed in a daily dose of $8 \mathrm{mg}$. Moreover, the data so far collected, show that curcumin has a very high activity not only in in vitro experiments, but also at the organismal level. This could be explained by its hormetic activity [36] Accordingly, it appears that curcumin is a very safe and beneficial nutraceutical spice which might fend off ageing and age-related diseases. However, at this time there is no data showing that any nutraceutical may influence ageing and lifespan, and complete randomized clinical trials in humans are also needed to confirm the potential use of curcumin in the prevention of diseases with an inflammation constituents, e.g. cardiovascular diseases, $\mathrm{AD}$, cardiometabolic syndrome, and ageing.

\section{Acknowledgements}

The meeting organizer Prof. C. Caruso is deeply indebted to all the speakers and chairpersons of the meeting who contributed to the scientific success of the symposium. In addition, on the day of the meeting the defense of $\mathrm{PhD}$ thesis of students belonging to the Pathobiology PhD course directed by CC were held. Prof. Caruso is proud of the hard and challenging work of his students whose motivation and enthusiasm, with the management of Drs. Giuseppina Candore, Giuseppina Colonna-Romano and Prof. Domenico Lio, have permitted to the whole Immunosenescence Unit to grow in the field of immunosenescence. This work was supported by the Polish Ministry of Science and Higher Education (grant N301 008 32/0549).

\section{Author details}

'Laboratory of Molecular Bases of Ageing, Nencki Institute of Experimental Biology, PAS, Warsaw, Poland. ${ }^{2}$ Department of Health Sciences, University of Molise, Campobasso, Italy. ${ }^{3}$ Geriatric Unit, Dept of Internal Medicine and Emergent Pathologies, University of Palermo, Palermo, Italy.

\section{Authors' contributions}

All the Authors drafted the manuscript and approved the final manuscript.

\section{Competing interests}

The authors declare that they have no competing interests. 
Received: 20 November 2009

Accepted: 17 January 2010 Published: 17 January 2010

\section{References}

1. Kirkwood TB: Evolution of ageing. Nature 1977, 270:301-304.

2. Holliday R: Aging is no longer an unsolved problem in biology. Ann N Y Acad Sci 2006, 1067:1-9.

3. Kirkwood TB: A systematic look at an old problem. Nature 2008, 451:644647.

4. Rattan SI: Increased molecular damage and heterogeneity as the basis of aging. Biol Chem 2008, 389:267-272.

5. Harman D: Aging: a theory based on free radical and radiation chemistry. J Gerontol 1956, 11:298-300.

6. Franceschi C, Bonafe M, Valensin S, Olivieri F, De Luca M, Ottaviani E, De Benedictis G: Inflamm-aging. An evolutionary perspective on immunosenescence. Ann N Y Acad Sci 2000, 908:244-254.

7. Meyer KC: Aging. Proc Am Thorac Soc 2005, 2:433-439.

8. Pawelec G, Derhovanessian E, Larbi A, Strindhall J, Wikby A: Cytomegalovirus and human immunosenescence. Rev Med Virol 2009, 19:47-56.

9. Coppe JP, Patil CK, Rodier F, Sun Y, Munoz DP, Goldstein J, Nelson PS, Desprez PY, Campisi J: Senescence-associated secretory phenotypes reveal cell-nonautonomous functions of oncogenic RAS and the p53 tumor suppressor. PLOS Biol 2008, 6:2853-2868.

10. Holliday R: The close relationship between biological aging and ageassociated pathologies in humans. J Gerontol A Biol Sci Med Sci 2004, 59 B543-546.

11. Chung HY, Sung B, Jung KJ, Zou Y, Yu BP: The molecular inflammatory process in aging. Antioxid Redox Signal 2006, 8:572-581.

12. Chung HY, Cesari M, Anton S, Marzetti E, Giovannini S, Seo AY, Carter C, Yu BP, Leeuwenburgh C: Molecular inflammation: underpinnings of aging and age-related diseases. Ageing Res Rev 2009, 8:18-30.

13. Vasto S, Candore G, Balistreri CR, Caruso M, Colonna-Romano G, Grimaldi MP, Listi F, Nuzzo D, Lio D, Caruso C: Inflammatory networks in ageing, age-related diseases and longevity. Mech Ageing Dev 2007, 128:83-91.

14. Mantovani A, Allavena P, Sica A, Balkwill F: Cancer-related inflammation. Nature 2008, 454:436-444.

15. Mantovani A: Cancer: Inflaming metastasis. Nature 2009, 457:36-37.

16. Hanahan D, Weinberg RA: The hallmarks of cancer. Cell 2000, 100:57-70.

17. Csiszar A, Wang M, Lakatta EG, Ungvari Z: Inflammation and endothelial dysfunction during aging: role of NF-kappaB. J Appl Physiol 2008, 105:1333-1341.

18. Finch CE, Morgan TE: Systemic inflammation, infection, ApoE alleles, and Alzheimer disease: a position paper. Curr Alzheimer Res 2007, 4:185-189.

19. Gupta A, Pansari K: Inflammation and Alzheimer's disease. Int J Clin Pract 2003, 57:36-39.

20. Vasto S, Candore G, Duro G, Lio D, Grimaldi MP, Caruso C: Alzheimer's disease and genetics of inflammation: a pharmacogenomic vision. Pharmacogenomics 2007, 8:1735-1745.

21. Hotamisligil GS: Inflammation and metabolic disorders. Nature 2006 444:860-867

22. Butler RN, Miller RA, Perry D, Carnes BA, Williams TF, Cassel C, Brody J, Bernard MA, Partridge L, Kirkwood T, Martin GM, Olshansky SJ: New model of health promotion and disease prevention for the 21st century. Bmj 2008, 337:a399.

23. Vijg J, Campisi J: Puzzles, promises and a cure for ageing. Nature 2008 454:1065-1071.

24. Ravindran J, Prasad S, Aggarwal BB: Curcumin and Cancer Cells: How Many Ways Can Curry Kill Tumor Cells Selectively?. Aaps J 2009, 3:495510

25. Salvioli S, Sikora E, Cooper EL, Franceschi C: Curcumin in Cell Death Processes: A Challenge for CAM of Age-Related Pathologies. Evid Based Complement Alternat Med 2007, 4:181-190.

26. Singh S: From exotic spice to modern drug?. Cell 2007, 130:765-768.

27. Aggarwal BB, Sundaram C, Malani N, Ichikawa H: Curcumin: the Indian solid gold. Adv Exp Med Biol 2007, 595:1-75.

28. Sikora E, Bielak-Zmijewska A, Mosieniak G, Piwocka K: The promise of slow down ageing may come from curcumin. Current Pharmacological Design 2010 .
29. Salminen A, Huuskonen J, Ojala J, Kauppinen A, Kaarniranta K, Suuronen T: Activation of innate immunity system during aging: NF-kB signaling is the molecular culprit of inflamm-aging. Ageing Res Rev 2008, 7:83-105.

30. Calabrese V, Bates TE, Mancuso C, Cornelius C, Ventimiglia B, Cambria MT, Di Renzo L, De Lorenzo A, Dinkova-Kostova AT: Curcumin and the cellular stress response in free radical-related diseases. Mol Nutr Food Res 2008, 52:1062-1073.

31. Cole GM, Teter B, Frautschy SA: Neuroprotective effects of curcumin. Adv Exp Med Biol 2007, 595:197-212.

32. Baum L, Lam CW, Cheung SK, Kwok T, Lui V, Tsoh J, Lam L, Leung V, Hui E, Ng C, Woo J, Chiu HF, Goggins WB, Zee BC, Cheng KF, Fong CY, Wong A, Mok H, Chow MS, Ho PC, Ip SP, Ho CS, Yu XW, Lai CY, Chan MH, Szeto S, Chan $\mathrm{IH}$, Mok V: Six-month randomized, placebo-controlled, doubleblind, pilot clinical trial of curcumin in patients with Alzheimer disease. $J$ Clin Psychopharmacol 2008, 28:110-113.

33. Yang F, Lim GP, Begum AN, Ubeda OJ, Simmons MR, Ambegaokar SS, Chen PP, Kayed R, Glabe CG, Frautschy SA, Cole GM: Curcumin inhibits formation of amyloid beta oligomers and fibrils, binds plaques, and reduces amyloid in vivo. J Biol Chem 2005, 280:5892-5901.

34. Chandra V, Pandav R, Dodge HH, Johnston JM, Belle SH, DeKosky ST, Ganguli M: Incidence of Alzheimer's disease in a rural community in India: the Indo-US study. Neurology 2001, 57:985-989.

35. Ng TP, Chiam PC, Lee T, Chua HC, Lim L, Kua EH: Curry consumption and cognitive function in the elderly. Am J Epidemiol 2006, 164:898-906.

36. Berge U, Kristensen P, Rattan SI: Hormetic modulation of differentiation of normal human epidermal keratinocytes undergoing replicative senescence in vitro. Exp Gerontol 2008, 43:658-662.

doi:10.1186/1742-4933-7-1

Cite this article as: Sikora et al.: Curcumin, inflammation, ageing and age-related diseases. Immunity \& Ageing 2010 7:1.

\section{Submit your next manuscript to BioMed Central and take full advantage of:}

- Convenient online submission

- Thorough peer review

- No space constraints or color figure charges

- Immediate publication on acceptance

- Inclusion in PubMed, CAS, Scopus and Google Scholar

- Research which is freely available for redistribution

Submit your manuscript at www.biomedcentral.com/submit
Biomed Centra 